\title{
On some new fixed point results in fuzzy $b$-metric spaces
}

\author{
Dušan Rakić ${ }^{1}$, Aiman Mukheimer ${ }^{2}$, Tatjana Došenović ${ }^{1}$,Zoran D. Mitrović ${ }^{3,4^{*}}$ and Stojan Radenović ${ }^{5}$
}

\section{"Correspondence:}

zoran.mitrovic@tdtu.edu.vn

${ }^{3}$ Nonlinear Analysis Research Group,

Ton Duc Thang University, Ho Chi

Minh City, Vietnam

${ }^{4}$ Faculty of Mathematics and

Statistics, Ton Duc Thang University,

Ho Chi Minh City, Vietnam

Full list of author information is

available at the end of the article

\begin{abstract}
This paper consists of several fixed point theorems in the fuzzy $b$-metric spaces. As an important result, we give a sufficient condition for a sequence to be Cauchy in the fuzzy $b$-metric space. Thus we simplify the proofs of many fixed point theorems in the fuzzy $b$-metric spaces with the well-known contraction conditions.
\end{abstract}

MSC: Primary 47H10; secondary 54H25; 05C 40

Keywords: Fixed point; Fuzzy metric space; Fuzzy $b$-metric space

\section{Introduction and preliminaries}

The notion of the fuzzy logic is introduced by Zadeh [31]. Unlike the theory of traditional logic, where some element does or does not belong to the set, in the fuzzy logic the affiliation of the element to the set is expressed as a number from the interval $[0,1]$. Uncertainty, as an essential part of a real problem, has prompted Zadeh to study the theory of the fuzzy sets to face the problem of indeterminacy. Theory of a fixed point in the fuzzy metric spaces can be viewed in different ways, and one of them is using a fuzzy logic. After Zadeh's result, Heilpern [13] represents the concept of the fuzzy mapping and proves a theorem on a fixed point for fuzzy contraction mapping in linear metric spaces, which represents a fuzzy generalization of Banach's contraction principle, followed by interest of many authors to study various contractions conditions within the framework of the fuzzy mapping. If the distance between the elements is not an exact number, then the imprecision is included in the metric, as it is introduced in the definition of fuzzy metric spaces introduced by Kaleva and Seikkala [14]. After that, first by Kramosil and Michalek [17] and further by George and Veeramani [6], the notion of a fuzzy metric space was introduced. For more details about fuzzy metric spaces and fixed point theorems in these spaces, among a huge number of the papers regarding this topic, we suggest for reading the papers $[5,8,19,21,22,25-27,30]$.

In addition to fuzzy metric spaces, there are still many extensions of metric and metric space terms. Bakhtin [1] and Czerwik [3] introduced a space where, instead of the triangle inequality, a weaker condition was observed, with the aim of generalization of the Banach contraction principle [2]. They called these spaces $b$-metric spaces. For more information about these spaces, we refer the readers to the papers $[15,18,20,28]$.

(c) The Author(s) 2020. This article is licensed under a Creative Commons Attribution 4.0 International License, which permits use sharing, adaptation, distribution and reproduction in any medium or format, as long as you give appropriate credit to the original author(s) and the source, provide a link to the Creative Commons licence, and indicate if changes were made. The images or other third party material in this article are included in the article's Creative Commons licence, unless indicated otherwise in a credit line to the material. If material is not included in the article's Creative Commons licence and your intended use is not permitted by statutory regulation or exceeds the permitted use, you will need to obtain permission directly from the copyright holder. To view a copy of this licence, visit http://creativecommons.org/licenses/by/4.0/. 
Relation between $b$-metric and fuzzy metric spaces is consider in [12]. On the other hand, in [23] the notion of a fuzzy $b$-metric space was introduced, where the triangle inequality is replaced by a weaker one. In this paper, we deal with this type of spaces. Using the notion of a countable extension of the $t$-norm, we prove a very useful lemma in the fuzzy $b$-metric space settings that ensure that a sequence $\left\{x_{n}\right\}$ is a Cauchy sequence. Using this lemma, we simplify the proofs of many well-known fixed point theorems. We present some of them in the main part of the paper.

We start with basic notions important for further work.

Definition 1.1 ([16]) A binary operation $T:[0,1] \times[0,1] \rightarrow[0,1]$ is a continuous $t$-norm if it satisfies the following conditions:

(t1) $T$ is associative and commutative,

(t2) $T$ is continuous,

(t3) $T(a, 1)=a$ for all $a \in[0,1]$,

(t4) $T(a, b) \leq T(c, d)$ for $a, b, c, d \in[0,1]$ such that $a \leq c$ and $b \leq d$.

Typical examples of a continuous $t$-norm are $T_{P}(a, b)=a \cdot b, T_{\min }(a, b)=\min \{a, b\}$ and $T_{L}(a, b)=\max \{a+b-1,0\}$.

Definition 1.2 ([9]) Let $T$ be a $t$-norm, and let $T_{n}:[0,1] \rightarrow[0,1], n \in \mathbb{N}$, be defined in the following way:

$$
T_{1}(x)=T(x, x), \quad T_{n+1}(x)=T\left(T_{n}(x), x\right), \quad n \in \mathbb{N}, x \in[0,1] .
$$

We say that a $t$-norm $T$ is of $H$-type if the family $\left\{T_{n}(x)\right\}_{n \in \mathbb{N}}$ is equicontinuous at $x=1$.

A trivial example of $t$-norm of $H$-type is $T_{\min }$; for a nontrivial example, see [9].

Each $t$-norm $T$ can be extended (see [16]) by associativity in a unique way to an $n$-ary operation taking for $\left(x_{1}, \ldots, x_{n}\right) \in[0,1]^{n}$ the values

$$
T_{i=1}^{1} x_{i}=x_{1}, \quad T_{i=1}^{n} x_{i}=T\left(T_{i=1}^{n-1} x_{i}, x_{n}\right)=T\left(x_{1}, x_{2}, \ldots, x_{n}\right) .
$$

Example 1.1 ([10]) $n$-ary extensions of the $t$-norms $T_{\min }, T_{L}$, and $T_{P}$, are the following:

$$
\begin{aligned}
& T_{\min }\left(x_{1}, \ldots, x_{n}\right)=\min \left(x_{1}, \ldots, x_{n}\right), \\
& T_{L}\left(x_{1}, \ldots, x_{n}\right)=\max \left(\sum_{i=1}^{n} x_{i}-(n-1), 0\right), \\
& T_{P}\left(x_{1}, \ldots, x_{n}\right)=\prod_{i=1}^{n} x_{i} .
\end{aligned}
$$

A $t$-norm $T$ (see [16]) can be extended to a countable infinite operation taking for any sequence $\left(x_{n}\right)_{n \in \mathbb{N}}$ from $[0,1]$ the value

$$
T_{i=1}^{\infty} x_{i}=\lim _{n \rightarrow \infty} T_{i=1}^{n} x_{i}
$$

The sequence $\left(T_{i=1}^{n} x_{i}\right)_{n \in \mathbb{N}}$ is nonincreasing and bounded from below, and hence the limit $T_{i=1}^{\infty} x_{i}$ exists.

In the fixed point theory (see $[10,11])$, it is of interest to investigate the classes of $t$-norms $T$ and sequences $\left(x_{n}\right)$ from the interval $[0,1]$ such that $\lim _{n \rightarrow \infty} x_{n}=1$ and

$$
\lim _{n \rightarrow \infty} T_{i=n}^{\infty} x_{i}=\lim _{n \rightarrow \infty} T_{i=1}^{\infty} x_{n+i}=1 .
$$


In [10] the following proposition is obtained.

Proposition 1.3 Let $\left(x_{n}\right)_{n \in \mathbb{N}}$ be a sequence of numbers from $[0,1]$ such that $\lim _{n \rightarrow \infty} x_{n}=1$, and let $T$ be a $t$-norm of $H$-type. Then $\lim _{n \rightarrow \infty} T_{i=n}^{\infty} x_{i}=\lim _{n \rightarrow \infty} T_{i=1}^{\infty} x_{n+i}=1$.

Definition 1.4 ([6,7]) A 3-tuple $(X, M, T)$ is called a fuzzy metric space if $X$ is an arbitrary (nonempty) set, $T$ is a continuous $t$-norm, and $M$ is a fuzzy set on $X^{2} \times(0, \infty)$ satisfying the following conditions for all $x, y, z \in X$ and $t, s>0$ :

(fm1) $M(x, y, t)>0$,

(fm2) $M(x, y, t)=1$ if and only if $x=y$,

(fm3) $M(x, y, t)=M(y, x, t)$,

(fm4) $T(M(x, y, t), M(y, z, s)) \leq M(x, z, t+s)$,

$(\mathrm{fm} 5) M(x, y, \cdot):(0, \infty) \rightarrow[0,1]$ is continuous.

Remark 1.5 In this paper, we use $X^{2}:=X \times X$.

Definition 1.6 ([23]) A 3-tuple $(X, M, T)$ is called a fuzzy $b$-metric space if $X$ is an arbitrary (nonempty) set, $T$ is a continuous $t$-norm, and $M$ is a fuzzy set on $X^{2} \times(0, \infty)$ satisfying the following conditions for all $x, y, z \in X, t, s>0$ and a given real number $b \geq 1$ :

(b1) $M(x, y, t)>0$,

(b2) $M(x, y, t)=1$ if and only if $x=y$,

(b3) $M(x, y, t)=M(y, x, t)$,

(b4) $T\left(M\left(x, y, \frac{t}{b}\right), M\left(y, z, \frac{s}{b}\right)\right) \leq M(x, z, t+s)$,

(b5) $M(x, y, \cdot):(0, \infty) \rightarrow[0,1]$ is continuous.

The class of fuzzy $b$-metric spaces is effectively larger than that of fuzzy metric spaces, since a fuzzy $b$-metric is a fuzzy metric when $b=1$.

The next example shows that a fuzzy $b$-metric on $X$ need not be a fuzzy metric on X.

Example 1.2 ([4]) Let $M(x, y, t)=e^{\frac{-|x-y|^{p}}{t}}$, where $p>1$ is a real number. Then $M$ is a fuzzy $b$-metric with $b=2^{p-1}$.

Noted that in the preceding example, for $p=2$, it is easy to see that $(X, M, T)$ is not a fuzzy metric space.

Example 1.3 ([4]) Let $M(x, y, t)=e^{\frac{-d(x, y)}{t}}$ or $M(x, y, t)=\frac{t}{t+d(x, y)}$, where $d$ is a $b$-metric on $X$, and let $T(a, c)=a \cdot c$ for $a, c \in[0,1]$. Then it is easy to show that $M$ is a fuzzy $b$-metric.

Before presentation of our main results, we give some definitions and proposition in a fuzzy $b$-metric space.

Definition 1.7 ([4]) A function $f: \mathbb{R} \rightarrow \mathbb{R}$ is called $b$-nondecreasing if $x>b y$ implies $f(x) \geq f(y)$ for all $x, y \in \mathbb{R}$.

Lemma $1.8([23,24])$ Let $M(x, y, \cdot)$ be a fuzzy b-metric space. Then $M(x, y, t)$ is $b$ nondecreasing with respect to $t$ for all $x, y \in X$. 
Definition $1.9([23,24])$ Let $(X, M, T)$ be a fuzzy $b$-metric space. For $t>0$, the open ball $B(x, r, t)$ with center $x \in X$ and radius $0<r<1$ is defined as

$$
B(x, r, t)=\{y \in X: M(x, y, t)>1-r\} .
$$

A sequence $\left\{x_{n}\right\}$ :

(a) converges to $x$ if $M\left(x_{n}, x, t\right) \rightarrow 1$ as $n \rightarrow \infty$ for each $t>0$. In this case, we write $\lim _{n \rightarrow \infty} x_{n}=x$;

(b) is called a Cauchy sequence if for all $0<\varepsilon<1$ and $t>0$, there exists $n_{0} \in \mathbb{N}$ such that $M\left(x_{n}, x_{m}, t\right)>1-\varepsilon$ for all $n, m \geq n_{0}$.

Definition $1.10([23,24])$ The fuzzy $b$-metric space $(X, M, T)$ is said to be complete if every Cauchy sequence is convergent.

Lemma $1.11([23,24])$ In a fuzzy b-metric space $(X, M, T)$ we have:

(i) If a sequence $\left\{x_{n}\right\}$ in $X$ converges to $x$, then $x$ is unique,

(ii) If a sequence $\left\{x_{n}\right\}$ in $X$ converges to $x$, then it is a Cauchy sequence.

In a fuzzy $b$-metric space we have the following proposition.

Proposition 1.12 ([24], Prop. 1.10) Let $(X, M, T)$ be a fuzzy b-metric space and suppose that $\left\{x_{n}\right\}$ converges to $x$. Then we have

$$
\begin{aligned}
& M\left(x, y, \frac{t}{b}\right) \leq \limsup _{n \rightarrow \infty} M\left(x_{n}, y, t\right) \leq M(x, y, b t), \\
& M\left(x, y, \frac{t}{b}\right) \leq \liminf _{n \rightarrow \infty} M\left(x_{n}, y, t\right) \leq M(x, y, b t) .
\end{aligned}
$$

Remark 1.13 In general, a fuzzy $b$-metric is not continuous.

Example 1.4 Let $X=[0, \infty), M(x, y, t)=e^{-\frac{d(x, y)}{t}}, T=T_{P}$, and

$$
d(x, y)= \begin{cases}0, & x=y, \\ 2|x-y|, & x, y \in[0,1) \\ \frac{1}{2}|x-y| & \text { otherwise. }\end{cases}
$$

Then $(X, M, T)$ is a fuzzy $b$-metric space with $b=4$. The $b$-metric $d$ in this example is taken from [29]. Note that the fuzzy $b$-metric $M$ is not continuous. Let us observe that

$$
\lim _{n \rightarrow \infty} M\left(1,1-\frac{1}{n}, t\right)=\lim _{n \rightarrow \infty} e^{-\frac{2}{n}}=1=M(1,1, t) .
$$

However, since

$$
\lim _{n \rightarrow \infty} M\left(0,1-\frac{1}{n}, t\right)=2 \lim _{n \rightarrow \infty}\left|1-\frac{1}{n}\right|=2 \neq \frac{1}{2}=M(0,1, t),
$$

$M(x, y, t)$ is not continuous. 


\section{Main results}

We will further use a fuzzy $b$-metric space in the sense of Definition 1.6 with additional condition $\lim _{t \rightarrow \infty} M(x, y, t)=1$.

Lemma 2.1 Let $\left\{x_{n}\right\}$ be a sequence in a fuzzy b-metric space $(X, M, T)$. Suppose that there exists $\lambda \in\left(0, \frac{1}{b}\right)$ such that

$$
M\left(x_{n}, x_{n+1}, t\right) \geq M\left(x_{n-1}, x_{n}, \frac{t}{\lambda}\right), \quad n \in \mathbb{N}, t>0,
$$

and there exist $x_{0}, x_{1} \in X$ and $v \in(0,1)$ such that

$$
\lim _{n \rightarrow \infty} T_{i=n}^{\infty} M\left(x_{0}, x_{1}, \frac{t}{v^{i}}\right)=1, \quad t>0 .
$$

Then $\left\{x_{n}\right\}$ is a Cauchy sequence.

Proof Let $\sigma \in(\lambda b, 1)$. Then the sum $\sum_{i=1}^{\infty} \sigma^{i}$ is convergent, and there exists $n_{0} \in \mathbb{N}$ such that $\sum_{i=n}^{\infty} \sigma^{i}<1$ for every $n>n_{0}$. Let $n>m>n_{0}$. Since $M$ is $b$-nondecreasing, by (b4), for every $t>0$, we have

$$
\begin{aligned}
M\left(x_{n}, x_{n+m}, t\right) \geq & M\left(x_{n}, x_{n+m}, \frac{t \sum_{i=n}^{n+m-1} \sigma^{i}}{b}\right) \\
\geq & T\left(M\left(x_{n}, x_{n+1}, \frac{t \sigma^{n}}{b^{2}}\right), M\left(x_{n+1}, x_{n+m}, \frac{t \sum_{i=n+1}^{n+m-1} \sigma^{i}}{b^{2}}\right)\right) \\
\geq & T\left(M\left(x_{n}, x_{n+1}, \frac{t \sigma^{n}}{b^{2}}\right), T\left(M\left(x_{n+1}, x_{n+2}, \frac{t \sigma^{n+1}}{b^{3}}\right),\right.\right. \\
& \left.\left.\ldots, M\left(x_{n+m-1}, x_{n+m}, \frac{t \sigma^{n+m-1}}{b^{m}}\right) \ldots\right)\right) .
\end{aligned}
$$

By (2.1) it follows that

$$
M\left(x_{n}, x_{n+1}, t\right) \geq M\left(x_{0}, x_{1}, \frac{t}{\lambda^{n}}\right), \quad n \in \mathbb{N}, t>0
$$

and since $n>m$ and $b>1$, we have

$$
\begin{aligned}
M\left(x_{n}, x_{n+m}, t\right) \geq & T\left(M\left(x_{0}, x_{1}, \frac{t \sigma^{n}}{b^{2} \lambda^{n}}\right), T\left(M\left(x_{0}, x_{1}, \frac{t \sigma^{n+1}}{b^{3} \lambda^{n+1}}\right),\right.\right. \\
& \left.\left.\ldots, M\left(x_{0}, x_{1}, \frac{t \sigma^{n+m-1}}{b^{m+1} \lambda^{n+m-1}}\right) \ldots\right)\right) \\
\geq & T_{i=n}^{n+m-1} M\left(x_{0}, x_{1}, \frac{t \sigma^{i}}{b^{i-n+2} \lambda^{i}}\right) \\
\geq & T_{i=n}^{n+m-1} M\left(x_{0}, x_{1}, \frac{t \sigma^{i}}{b^{i} \lambda^{i}}\right) \geq T_{i=n}^{\infty} M\left(x_{0}, x_{1}, \frac{t}{v^{i}}\right),
\end{aligned}
$$

where $v=\frac{b \lambda}{\sigma}$. Since $v \in(0,1)$, by $(2.2)$ it follows that $\left\{x_{n}\right\}$ is a Cauchy sequence.

By Proposition 1.3 the next corollary immediately follows. 
Corollary 2.2 Let $\left\{x_{n}\right\}$ be a sequence in a fuzzy b-metric space $(X, M, T)$, and let $T$ be of $H$-type. If there exists $\lambda \in\left(0, \frac{1}{b}\right)$ such that

$$
M\left(x_{n}, x_{n+1}, t\right) \geq M\left(x_{n-1}, x_{n}, \frac{t}{\lambda}\right), \quad n \in \mathbb{N}, t>0,
$$

then $\left\{x_{n}\right\}$ is a Cauchy sequence.

Lemma 2.3 Iffor some $\lambda \in(0,1)$ and $x, y \in X$,

$$
M(x, y, t) \geq M\left(x, y, \frac{t}{\lambda}\right), \quad t>0
$$

then $x=y$.

Proof Condition (2.4) implies that

$$
M(x, y, t) \geq M\left(x, y, \frac{t}{\lambda^{n}}\right), \quad n \in \mathbb{N}, t>0 .
$$

Now

$$
M(x, y, t) \geq \lim _{n \rightarrow \infty} M\left(x, y, \frac{t}{\lambda^{n}}\right)=1, \quad t>0,
$$

and by (b1) it follows that $x=y$.

Theorem 2.4 Let $(X, M, T)$ be a complete fuzzy b-metric space, and let $f: X \rightarrow X$. Suppose that there exists $\lambda \in\left(0, \frac{1}{b}\right)$ such that

$$
M(f x, f y, t) \geq M\left(x, y, \frac{t}{\lambda}\right), \quad x, y \in X, t>0,
$$

and there exist $x_{0} \in X$ and $v \in(0,1)$ such that

$$
\lim _{n \rightarrow \infty} T_{i=n}^{\infty} M\left(x_{0}, f x_{0}, \frac{t}{v^{i}}\right)=1, \quad t>0 .
$$

Then $f$ has a unique fixed point in $X$.

Proof Let $x_{0} \in X$ and $x_{n+1}=f x_{n}, n \in \mathbb{N}$. If we take $x=x_{n}$ and $y=x_{n-1}$ in (2.5), then we have

$$
M\left(x_{n}, x_{n+1}, t\right) \geq M\left(x_{n-1}, x_{n}, \frac{t}{\lambda}\right), \quad n \in \mathbb{N}, t>0,
$$

and by Lemma 2.1 it follows that $\left\{x_{n}\right\}$ is a Cauchy sequence. Since $(X, M, T)$ is complete, there exists $x \in X$ such that

$$
\lim _{n \rightarrow \infty} x_{n}=x \text { and } \lim _{n \rightarrow \infty} M\left(x, x_{n}, t\right)=1, \quad t>0 .
$$


Conditions (2.5) and (b4) are used to show that $x$ is a fixed point for $f$ :

$$
\begin{aligned}
M(f x, x, t) & \geq T\left(M\left(f x, x_{n}, \frac{t}{2 b}\right), M\left(x_{n}, x, \frac{t}{2 b}\right)\right) \\
& \geq T\left(M\left(x, x_{n-1}, \frac{t}{2 b \lambda}\right), M\left(x_{n}, x, \frac{t}{2 b}\right)\right)
\end{aligned}
$$

for all $t>0$. By (2.7), as $n \rightarrow \infty$, we get

$$
M(f x, x, t) \geq T(1,1)=1 .
$$

Suppose that $x$ and $y$ are fixed points for $f$. By (2.5) we have

$$
M(x, y, t)=M(f x, f y, t) \geq M\left(x, y, \frac{t}{\lambda}\right), \quad t>0,
$$

and Lemma 2.3 implies that $x=y$.

Example 2.1 Let $X=[0,1]$. By Example 1.2, for $p=2$, it follows that $(X, M, T)$ is a fuzzy $b$-metric space with $b=2$ and fuzzy $b$-metric

$$
M(x, y, t)=e^{-\frac{(x-y)^{2}}{t}}, \quad x, y \in X, t>0 .
$$

Let $f(x)=k x, k<\frac{\sqrt{2}}{2}, x \in X$. Then

$$
M(f x, f y, t)=e^{-\frac{k^{2}(x-y)^{2}}{t}} \geq e^{-\frac{\lambda(x-y)^{2}}{t}}=M\left(x, y, \frac{t}{\lambda}\right), \quad x, y \in X, t>0,
$$

for $\frac{1}{b}>\lambda>k^{2}$. So, condition (2.5) of Theorem 2.4 is fulfilled, and $f$ has a unique fixed point in $X$.

Theorem 2.5 Let $(X, M, T)$ is a complete fuzzy $b$-metric space, and let $f: X \rightarrow X$. Suppose that there exists $\lambda \in\left(0, \frac{1}{b}\right)$ such that

$$
M(f x, f y, t) \geq \min \left\{M\left(x, y, \frac{t}{\lambda}\right), M\left(f x, x, \frac{t}{\lambda}\right), M\left(f y, y, \frac{t}{\lambda}\right)\right\}
$$

for all $x, y \in X, t>0$, and there exist $x_{0} \in X$ and $v \in(0,1)$ such that

$$
\lim _{n \rightarrow \infty} T_{i=n}^{\infty} M\left(x_{0}, f x_{0}, \frac{t}{v^{i}}\right)=1
$$

for all $t>0$. Then $f$ has a unique fixed point in $X$.

Proof Let $x_{0} \in X$ and $x_{n+1}=f x_{n}, n \in \mathbb{N}$. By (2.8) with $x=x_{n}$ and $y=x_{n-1}$, for every $n \in \mathbb{N}$ and every $t>0$, we have

$$
\begin{aligned}
M\left(x_{n+1}, x_{n}, t\right) & \geq \min \left\{M\left(x_{n}, x_{n-1}, \frac{t}{\lambda}\right), M\left(x_{n+1}, x_{n}, \frac{t}{\lambda}\right), M\left(x_{n}, x_{n-1}, \frac{t}{\lambda}\right)\right\} \\
& \geq \min \left\{M\left(x_{n}, x_{n-1}, \frac{t}{\lambda}\right), M\left(x_{n+1}, x_{n}, \frac{t}{\lambda}\right)\right\} .
\end{aligned}
$$


If $M\left(x_{n+1}, x_{n}, t\right) \geq M\left(x_{n+1}, x_{n}, \frac{t}{\lambda}\right), n \in \mathbb{N}, t>0$, then by Lemma 2.3 it follows that $x_{n}=x_{n+1}$, $n \in \mathbb{N}$. So,

$$
M\left(x_{n+1}, x_{n}, t\right) \geq M\left(x_{n}, x_{n-1}, \frac{t}{\lambda}\right), \quad n \in \mathbb{N}, t>0,
$$

and by Lemma 2.1 we have that $\left\{x_{n}\right\}$ is a Cauchy sequence. Hence there exists $x \in X$ such that

$$
\lim _{n \rightarrow \infty} x_{n}=x \text { and } \lim _{n \rightarrow \infty} M\left(x, x_{n}, t\right)=1, \quad t>0 .
$$

Let us prove that $x$ is a fixed point for $f$. Let $\sigma_{1} \in(\lambda b, 1)$ and $\sigma_{2}=1-\sigma_{1}$. By (2.8) we have

$$
\begin{aligned}
M(f x, x, t) \geq & T\left(M\left(f x, f x_{n}, \frac{t \sigma_{1}}{b}\right), M\left(x_{n+1}, x, \frac{t \sigma_{2}}{b}\right)\right) \\
\geq & T\left(\min \left\{M\left(x, x_{n}, \frac{t \sigma_{1}}{b \lambda}\right), M\left(x, f x, \frac{t \sigma_{1}}{b \lambda}\right), M\left(x_{n}, x_{n+1}, \frac{t \sigma_{1}}{b \lambda}\right)\right\}\right. \\
& \left.M\left(x_{n+1}, x, \frac{t \sigma_{2}}{b}\right)\right) .
\end{aligned}
$$

Taking $n \rightarrow \infty$ and using (2.10), we get

$$
\begin{aligned}
M(f x, x, t) & \geq T\left(\min \left\{1, M\left(x, f x, \frac{t \sigma_{1}}{b \lambda}\right), 1\right\}, 1\right) \\
& =T\left(M\left(x, f x, \frac{t \sigma_{1}}{b \lambda}\right), 1\right)=M\left(x, f x, \frac{t}{v}\right), \quad t>0,
\end{aligned}
$$

where $v=\frac{b \lambda}{\sigma_{1}} \in(0,1)$. So,

$$
M(f x, x, t) \geq M\left(f x, x, \frac{t}{v}\right), \quad t>0
$$

and by Lemma 2.3 it follows that $f x=x$.

Suppose that $x$ and $y$ are fixed points for $f$, that is, $f x=x$ and $f y=y$. By condition (2.8) we get

$$
\begin{aligned}
M(f x, f y, t) & \geq \min \left\{M\left(x, y, \frac{t}{\lambda}\right), M\left(x, f x, \frac{t}{\lambda}\right), M\left(y, f y, \frac{t}{\lambda}\right)\right\} \\
& =\min \left\{M\left(x, y, \frac{t}{\lambda}\right), 1,1\right\}=M\left(x, y, \frac{t}{\lambda}\right)=M\left(f x, f y, \frac{t}{\lambda}\right)
\end{aligned}
$$

for $t>0$, and by Lemma 2.3 it follows that $f x=f y$, that is, $x=y$.

Example 2.2 Let $X=(0,2), M(x, y, t)=e^{-\frac{(x-y)^{2}}{t}}, T=T_{P}$. Then $(X, M, T)$ is a complete $b$ fuzzy metric space with $b=2$. Let

$$
f(x)= \begin{cases}2-x, & x \in(0,1) \\ 1, & x \in[1,2)\end{cases}
$$


Case 1. If $x, y \in[1,2)$, then $M(f x, f y, t)=1, t>0$, and conditions (2.8) are trivially satisfied. Case 2. If $x \in[1,2)$ and $y \in(0,1)$, then, for $\lambda \in\left(\frac{1}{4}, \frac{1}{2}\right)$, we have

$$
M(f x, f y, t)=e^{-\frac{(1-y)^{2}}{t}} \geq e^{-\frac{4 \lambda(1-y)^{2}}{t}}=M\left(f y, y, \frac{t}{\lambda}\right), \quad t>0 .
$$

Case 3. As in the previous case, for $\lambda \in\left(\frac{1}{4}, \frac{1}{2}\right)$, we have

$$
M(f x, f y, t) \geq M\left(f x, x, \frac{t}{\lambda}\right), \quad x \in(0,1), y \in[1,2), t>0 .
$$

Case 4. If $x, y \in(0,1)$, then, for $\lambda \in\left(\frac{1}{4}, \frac{1}{2}\right)$,

$$
M(f x, f y, t)=e^{-\frac{(x-y)^{2}}{t}} \geq e^{-\frac{(1-y)^{2}}{t}} \geq e^{-\frac{4 \lambda(1-y)^{2}}{t}}=M\left(f y, y, \frac{t}{\lambda}\right), \quad x>y, t>0,
$$

and

$$
M(f x, f y, t) \geq M\left(f x, x, \frac{t}{\lambda}\right), \quad x<y, t>0
$$

So conditions (2.8) are satisfied for all $x, y \in X, t>0$, and by Theorem 2.5 it follows that $x=1$ is a unique fixed point for $f$.

In the next theorem, we observe a Ćirić quasicontraction in a fuzzy $b$-metric space.

Theorem 2.6 Let $\left(X, M, T_{\min }\right)$ be a complete fuzzy $b$-metric space, and let $f: X \rightarrow X$. If for some $\lambda \in\left(0, \frac{1}{b^{2}}\right)$,

$$
\begin{aligned}
M(f x, f y, t) \geq & \min \left\{M\left(x, y, \frac{t}{\lambda}\right), M\left(f x, x, \frac{t}{\lambda}\right), M\left(f y, y, \frac{t}{\lambda}\right),\right. \\
& \left.M\left(f x, y, \frac{2 t}{\lambda}\right), M\left(x, f y, \frac{t}{\lambda}\right)\right\}, \quad x, y \in X, t>0,
\end{aligned}
$$

then $f$ has a unique fixed point in $X$.

Proof Let $x_{0} \in X$ and $x_{n+1}=f x_{n}, n \in \mathbb{N}$. By (2.11) with $x=x_{n}$ and $y=x_{n-1}$, using (b4) and the assumption that $T=T_{\min }$, we have

$$
\begin{aligned}
M\left(x_{n+1}, x_{n}, t\right) \geq & \min \left\{M\left(x_{n}, x_{n-1}, \frac{t}{\lambda}\right), M\left(x_{n+1}, x_{n}, \frac{t}{\lambda}\right), M\left(x_{n}, x_{n-1}, \frac{t}{\lambda}\right),\right. \\
& \left.\min \left\{M\left(x_{n+1}, x_{n}, \frac{t}{b \lambda}\right), M\left(x_{n}, x_{n-1}, \frac{t}{b \lambda}\right)\right\}, M\left(x_{n}, x_{n}, \frac{t}{\lambda}\right)\right\} \\
\geq & \min \left\{M\left(x_{n}, x_{n-1}, \frac{t}{b \lambda}\right), M\left(x_{n+1}, x_{n}, \frac{t}{b \lambda}\right)\right\}, \quad n \in \mathbb{N}, t>0 .
\end{aligned}
$$

As in the proof of Theorem 2.5, by Lemma 2.3 and Corollary 2.2 it follows that

$$
M\left(x_{n+1}, x_{n}, t\right) \geq M\left(x_{n}, x_{n-1}, \frac{t}{b \lambda}\right), \quad n \in \mathbb{N}, t>0,
$$


and $\left\{x_{n}\right\}$ is a Cauchy sequence. So there exists $x \in X$ such that

$$
\lim _{n \rightarrow \infty} x_{n}=x \quad \text { and } \quad \lim _{n \rightarrow \infty} M\left(x, x_{n}, t\right)=1, \quad t>0 .
$$

Let $\sigma_{1} \in\left(b^{2} \lambda, 1\right)$ and $\sigma_{2}=1-\sigma_{1}$. By (2.11) and (b4) for $T=T_{\min }$, we have

$$
\begin{aligned}
M(f x, x, t) \geq & \min \left\{M\left(f x, f x_{n}, \frac{t \sigma_{1}}{b}\right), M\left(f x_{n}, x, \frac{t \sigma_{2}}{b}\right)\right\} \\
\geq & \min \left\{\operatorname { m i n } \left\{M\left(x, x_{n}, \frac{t \sigma_{1}}{b \lambda}\right), M\left(x, f x, \frac{t \sigma_{1}}{b \lambda}\right), M\left(x_{n}, x_{n+1}, \frac{t \sigma_{1}}{b \lambda}\right),\right.\right. \\
& \left.\min \left\{M\left(f x, x, \frac{t \sigma_{1}}{b^{2} \lambda}\right), M\left(x, x_{n}, \frac{t \sigma_{1}}{b^{2} \lambda}\right)\right\}, M\left(x, x_{n+1}, \frac{t \sigma_{1}}{b \lambda}\right)\right\} \\
& \left.M\left(x_{n+1}, x, \frac{t \sigma_{2}}{b}\right)\right\}
\end{aligned}
$$

for all $n \in \mathbb{N}$ and $t>0$. Taking $n \rightarrow \infty$ and using (2.12), we get

$$
\begin{aligned}
M(f x, x, t) & \geq \min \left\{\min \left\{1, M\left(x, f x, \frac{t \sigma_{1}}{b \lambda}\right), 1, \min \left\{M\left(f x, x, \frac{t \sigma_{1}}{b^{2} \lambda}\right), 1\right\}, 1\right\}, 1\right\} \\
& =M\left(f x, x, \frac{t \sigma_{1}}{b^{2} \lambda}\right), \quad t>0,
\end{aligned}
$$

and by Lemma 2.3 with $v=\frac{b^{2} \lambda}{\sigma_{1}} \in(0,1)$ it follows that $f x=x$.

By condition (2.11), for two fixed points $x=f x$ and $y=f y$, we have

$$
\begin{aligned}
M(f x, f y, t) \geq & \min \left\{M\left(x, y, \frac{t}{\lambda}\right), M\left(f x, x, \frac{t}{\lambda}\right), M\left(f y, y, \frac{t}{\lambda}\right),\right. \\
& \left.\min \left\{M\left(f x, x, \frac{t}{b \lambda}\right), M\left(x, y, \frac{t}{b \lambda}\right)\right\}, M\left(x, f y, \frac{t}{\lambda}\right)\right\} \\
= & \min \left\{M\left(x, y, \frac{t}{\lambda}\right), 1,1, \min \left\{1, M\left(x, y, \frac{t}{b \lambda}\right)\right\}, M\left(x, y, \frac{t}{\lambda}\right)\right\} \\
= & M\left(x, y, \frac{t}{b \lambda}\right)=M\left(f x, f y, \frac{t}{b \lambda}\right), \quad t>0,
\end{aligned}
$$

and by Lemma 2.3 it follows that $x=y$.

Remark 2.7 If the quasicontractive condition holds, then we come to the conclusion that only by using the $t$-norm does the minimum ensure the existence of a unique fixed point. It was of interest to determine for which $\lambda$ contractive condition (2.11) ensures the existence of a unique fixed point. Since the $t$-norm of the minimum is the strongest $t$-norm, and as for the fixed point such results are of least interest, in the next theorem, we give a weaker contraction condition than the quasicontraction, which ensures the existence of a fixed point, for a wider class of $t$-norms.

In the following theorem with the weaker $t$-norm, we propose a new contractive condition. 
Theorem 2.8 Let $(X, M, T), T \geq T_{P}$, be a complete fuzzy b-metric space, and let $f: X \rightarrow X$. Suppose that for some $\lambda \in\left(0, \frac{1}{b^{2}}\right)$,

$$
\begin{aligned}
M(f x, f y, t) \geq & \min \left\{M\left(x, y, \frac{t}{\lambda}\right), M\left(f x, x, \frac{t}{\lambda}\right), M\left(f y, y, \frac{t}{\lambda}\right),\right. \\
& \left.\sqrt{M\left(f x, y, \frac{2 t}{\lambda}\right)}, M\left(x, f y, \frac{t}{\lambda}\right)\right\}, \quad x, y \in X, t>0,
\end{aligned}
$$

and there exist $x_{0} \in X$ and $v \in(0,1)$ such that

$$
\lim _{n \rightarrow \infty} T_{i=n}^{\infty} M\left(x_{0}, f x_{0}, \frac{t}{v^{i}}\right)=1, \quad t>0
$$

Then $f$ has a unique fixed point in $X$.

Proof Let $x_{0} \in X$ and $x_{n+1}=f x_{n}, n \in \mathbb{N}$. Taking $x=x_{n}$ and $y=x_{n-1}$ in condition (2.13), by (b4) and $T \geq T_{P}$ we have

$$
\begin{aligned}
M\left(x_{n+1}, x_{n}, t\right) \geq & \min \left\{M\left(x_{n}, x_{n-1}, \frac{t}{\lambda}\right), M\left(x_{n+1}, x_{n}, \frac{t}{\lambda}\right), M\left(x_{n}, x_{n-1}, \frac{t}{\lambda}\right),\right. \\
& \left.\sqrt{M\left(x_{n+1}, x_{n}, \frac{t}{b \lambda}\right) \cdot M\left(x_{n}, x_{n-1}, \frac{t}{b \lambda}\right)}, M\left(x_{n}, x_{n}, \frac{t}{\lambda}\right)\right\}, \quad n \in \mathbb{N}, t>0 .
\end{aligned}
$$

Since $M(x, y, t)$ is $b$-nondecreasing in $t$ and $\sqrt{a \cdot b} \geq \min \{a, b\}$, we obtain that

$$
M\left(x_{n+1}, x_{n}, t\right) \geq \min \left\{M\left(x_{n+1}, x_{n}, \frac{t}{b \lambda}\right), M\left(x_{n}, x_{n-1}, \frac{t}{b \lambda}\right)\right\}
$$

for all $n \in \mathbb{N}, t>0$. By Lemmas 2.3 and 2.1 it follows that

$$
M\left(x_{n+1}, x_{n}, t\right) \geq M\left(x_{n}, x_{n-1}, \frac{t}{b \lambda}\right), \quad n \in \mathbb{N}, t>0,
$$

and $\left\{x_{n}\right\}$ is a Cauchy sequence. Since $(X, M, T)$ is a complete space, there exists $x \in X$ such that

$$
\lim _{n \rightarrow \infty} x_{n}=x \quad \text { and } \quad \lim _{n \rightarrow \infty} M\left(x, x_{n}, t\right)=1, \quad t>0 .
$$

Let $\sigma_{1} \in\left(b^{2} \lambda, 1\right)$ and $\sigma_{2}=1-\sigma_{1}$. By (2.13) and (b4) for $T \geq T_{P}$, we have

$$
\begin{aligned}
M(f x, x, t) \geq & T\left(M\left(f x, f x_{n}, \frac{t \sigma_{1}}{b}\right), M\left(f x_{n}, x, \frac{t \sigma_{2}}{b}\right)\right) \\
\geq & T\left(\operatorname { m i n } \left\{M\left(x, x_{n}, \frac{t \sigma_{1}}{b \lambda}\right), M\left(x, f x, \frac{t \sigma_{1}}{b \lambda}\right), M\left(x_{n}, x_{n+1}, \frac{t \sigma_{1}}{b \lambda}\right)\right.\right. \\
& \left.\sqrt{M\left(f x, x, \frac{t \sigma_{1}}{b^{2} \lambda}\right) \cdot M\left(x, x_{n}, \frac{t \sigma_{1}}{b^{2} \lambda}\right)}, M\left(x, x_{n+1}, \frac{t \sigma_{1}}{b \lambda}\right)\right\} \\
& \left.M\left(x_{n+1}, x, \frac{t \sigma_{2}}{b}\right)\right)
\end{aligned}
$$




$$
\begin{aligned}
\geq & T\left(\operatorname { m i n } \left\{M\left(x, x_{n}, \frac{t \sigma_{1}}{b \lambda}\right), M\left(x, f x, \frac{t \sigma_{1}}{b \lambda}\right), M\left(x_{n}, x_{n+1}, \frac{t \sigma_{1}}{b \lambda}\right),\right.\right. \\
& \min \left\{M\left(f x, x, \frac{t \sigma_{1}}{b^{2} \lambda}\right), M\left(x, x_{n}, \frac{t \sigma_{1}}{b^{2} \lambda}\right)\right\}, M\left(x, x_{n+1}, \frac{t \sigma_{1}}{b \lambda}\right), \\
& \left.M\left(x_{n+1}, x, \frac{t \sigma_{2}}{b}\right)\right\}
\end{aligned}
$$

for all $n \in \mathbb{N}$ and $t>0$. Taking $n \rightarrow \infty$ and using (2.15), we get

$$
\begin{aligned}
M(f x, x, t) & \geq T\left(\min \left\{1, M\left(x, f x, \frac{t \sigma_{1}}{b \lambda}\right), 1, \min \left\{M\left(f x, x, \frac{t \sigma_{1}}{b^{2} \lambda}\right), 1\right\}, 1\right\}, 1\right) \\
& =M\left(f x, x, \frac{t \sigma_{1}}{b^{2} \lambda}\right), \quad t>0,
\end{aligned}
$$

and by Lemma 2.3 with $v=\frac{b^{2} \lambda}{\sigma_{1}} \in(0,1)$ it follows that $f x=x$.

Suppose that $x$ and $y$ are fixed points for $f$. By condition (2.13) we have

$$
\begin{aligned}
M(f x, f y, t) \geq & T\left(M\left(x, y, \frac{t}{\lambda}\right), M\left(f x, x, \frac{t}{\lambda}\right), M\left(f y, y, \frac{t}{\lambda}\right),\right. \\
& \sqrt{\left.M\left(f x, x, \frac{t}{b \lambda}\right), M\left(x, y, \frac{t}{b \lambda}\right), M\left(x, f y, \frac{t}{\lambda}\right)\right)} \\
\geq & T\left(M\left(x, y, \frac{t}{\lambda}\right), 1,1, \min \left\{1, M\left(x, y, \frac{t}{b \lambda}\right)\right\}, M\left(x, y, \frac{t}{\lambda}\right)\right) \\
= & M\left(x, y, \frac{t}{b \lambda}\right)=M\left(f x, f y, \frac{t}{b \lambda}\right), \quad t>0,
\end{aligned}
$$

and thus by Lemma 2.3 it follows that $x=y$.

Example 2.3 Let $X=\{0,1,3\}, M(x, y, t)=e^{-\frac{(x-y)^{2}}{t}}, T=T_{P}$. Then $(X, M, T)$ is a complete $b$-fuzzy metric space with $b=2$. Define the function $f: X \rightarrow X$ as follows: $f 0=f 1=1$, $f 3=0$.

Observe that if $x=y$ or $x, y \in\{0,1\}$, then $M(f x, f y, t)=1, t>0$, and condition (2.13) is fulfilled.

Let $x=1$ and $y=3$. Then since $\lambda \in\left(\frac{1}{9}, \frac{1}{4}\right)$, we have that

$$
M(f x, f y, t)=e^{-\frac{1}{t}} \geq \min \left\{e^{-\frac{9 \lambda}{t}}, e^{-\frac{\lambda}{t}}, e^{-\frac{9 \lambda}{t}}, e^{-\frac{\lambda}{t}}, 1\right\} .
$$

Let $x=1$ and $y=3$. Then selecting $\lambda$ from the interval $\left(\frac{1}{9}, \frac{1}{4}\right)$, we get that

$$
M(f x, f y, t)=e^{-\frac{1}{t}} \geq \min \left\{e^{-\frac{4 \lambda}{t}}, 1, e^{-\frac{9 \lambda}{t}}, e^{-\frac{\lambda}{t}}, e^{-\frac{\lambda}{t}}\right\} .
$$

Similarly, if $x=3$ and $y=1$ as well as $x=3$ and $y=1$, we conclude that for $\lambda \in\left(\frac{1}{9}, \frac{1}{4}\right)$, condition (2.13) is fulfilled for all $x, y \in X$ and $t>0$.

Therefore all conditions of Theorem 2.8 are satisfied, and $x=1$ is a unique fixed point.

Remark 2.9 Open problem: Find an example that supports Theorem 2.8 but conditions (2.1) and (2.8) are not satisfied. 


\title{
Remark 2.10 Finally, we can ask the following question:
}

Prove Lemma 2.1 for the case $\lambda \in[1 / b, 1)$.

\begin{abstract}
Acknowledgements
The first and third authors are supported by the project Ministries of Education, Science and Technology Development, Project Number 451-03-68 / 2020-14 / 200134. The second author would like to thank Prince Sultan University for funding this work through the research group Nonlinear Analysis Methods in Applied Mathematics (NAMAM) Group Number RG-DES-2017-01-17.

Funding

No external funding.

Availability of data and materials

Not applicable.

Competing interests

The authors declare no conflict of interest.

Authors' contributions

All authors contributed equally in writing this paper. All authors read and approved the final manuscript.

\section{Author details}

${ }^{1}$ Faculty of Technology, University of Novi Sad, Novi Sad, Serbia. ${ }^{2}$ Department of Mathematics and General Sciences, Prince Sultan University, Riyadh, Saudi Arabia. ${ }^{3}$ Nonlinear Analysis Research Group, Ton Duc Thang University, Ho Chi Minh City, Vietnam. ${ }^{4}$ Faculty of Mathematics and Statistics, Ton Duc Thang University, Ho Chi Minh City, Vietnam.

${ }^{5}$ Faculty of Mechanical Engineering, University of Belgrade, Beograd, Serbia.
\end{abstract}

\section{Publisher's Note}

Springer Nature remains neutral with regard to jurisdictional claims in published maps and institutional affiliations.

Received: 3 July 2019 Accepted: 7 April 2020 Published online: 15 April 2020

\section{References}

1. Bakhtin, I.A.: The contraction principle in quasimetric spaces. Funct. Anal. 30, 26-37 (1989)

2. Banach, S.: Sur les opérations dans les ensembles abstraits et leur application aux équations intégrales. Fundam. Math. 3, 133-181 (1922)

3. Czerwik, S.: Contraction mappings in b-metric spaces. Acta Math. Inform. Univ. Ostrav. 1(1), 5-11 (1993)

4. Došenović, T., Javaheri, A., Sedghi, S., Shobe, N.: Coupled fixed point theorem in b-fuzzy metric spaces. Novi Sad J. Math. 47(1), 77-88 (2017)

5. Došenović, T., Rakić, D., Brdar, M.: Fixed point theorem in fuzzy metric spaces using altering distance. Filomat 28(7), 1517-1524 (2014)

6. George, A., Veeramani, P.: On some result in fuzzy metric space. Fuzzy Sets Syst. 64, 395-399 (1994)

7. George, A., Veeramani, P.: On some results of analysis for fuzzy metric spaces. Fuzzy Sets Syst. 90, 365-368 (1997)

8. Gregori, V., Sapena, A.: On fixed-point theorem in fuzzy metric spaces. Fuzzy Sets Syst. 125, 245-252 (2002)

9. Hadžić, O.: A fixed point theorem in Menger spaces. Publ. Inst. Math. (Belgr.) 20, 107-112 (1979)

10. Hadžić, O., Pap, E.: Fixed Point Theory in Probabilistic Metric Spaces. Kluwer Academic, Dordrecht (2001)

11. Hadžić, O., Pap, E., Budinčević, M.: Countable extension of triangular norms and their applications to the fixed point theory in probabilistic metric spaces. Kybernetika 38(3), 363-382 (2002) Uncertainty modelling, 2001 (Bratislava)

12. Hassanzadeh, Z., Sedghi, S.: Relation between b-metric and fuzzy metric spaces. Math. Morav. 22(1), 55-63 (2018)

13. Heilpern, S.: Fuzzy mappings and fixed point theorem. J. Math. Anal. Appl. 83(2), 566-569 (1981)

14. Kaleva, O., Seikkala, S.: On fuzzy metric spaces. Fuzzy Sets Syst. 12, 215-229 (1984)

15. Kirk, W., Shahzad, N.: Fixed Point Theory in Distance Spaces. Springer, Switzerland (2014)

16. Klement, E.P., Mesiar, R., Pap, E.: Triangular Norms. Trends in Logic, vol. 8. Kluwer Academic, Dordrecht (2000)

17. Kramosil, I., Michalek, J.: Fuzzy metric and statistical metric spaces. Kybernetica 11, 326-334 (1975)

18. Miculescu, R., Mihail, A.: New fixed point theorems for set-valued contractions in b-metric spaces. J. Fixed Point Theory Appl. 19, 2153-2163 (2017)

19. Miheț, D.: A Banach contraction theorem in fuzzy metric spaces. Fuzzy Sets Syst. 144, 431-439 (2004)

20. Mitrović, Z.D.: A note on the result of Suzuki, Miculescu and Mihail. J. Fixed Point Theory Appl. (2019). https://doi.org/10.1007/s11784-019-0663-5

21. Roldán-López-de-Hierro, A.-F., Karapınar, E., Kumam, P.: Irremissible stimulate on 'Unified fixed point theorems in fuzzy metric spaces via common limit range property.' J. Inequal. Appl. 2014, Paper No. 257, 7 p. (2014)

22. Roldán-López-de-Hierro, A.-F., Karapınar, E., Manro, S.: Some new fixed point theorems in fuzzy metric spaces. J. Intell. Fuzzy Syst. 27(5), 2257-2264 (2014)

23. Sedghi, S., Shobe, N.: Common fixed point theorem in b-fuzzy metric space. Nonlinear Funct. Anal. Appl. 17(3), 349-359 (2012)

24. Sedghi, S., Shobe, N.: Common fixed point theorem for $R$-weakly commuting maps in $b$-fuzzy metric space. Nonlinear Funct. Anal. Appl. 19(2), 285-295 (2014)

25. Sedghi, S., Shobe, N., Selahshoor, M.A.: A common fixed point theorem for Four mappings in two complete fuzzy metric spaces. Adv. Fuzzy Math. 1(1) (2006) 
26. Sedghi, S., Shobkolaei, N., Došenović, T., Radenović, S.: Suzuki-type of common fixed point theorems in fuzzy metric spaces. Math. Slovaca 68(2), 451-462 (2018)

27. Sedghi, S., Turkoglu, D., Shobe, N.: Generalization common fixed point theorem in complete fuzzy metric spaces. J. Comput. Anal. Appl. 3(9), 337-348 (2007)

28. Suzuki, T.: Basic inequality on a b-metric space and its applications. J. Inequal. Appl. 2017(1), 256 (2017). https://doi.org/10.1186/s13660-017-1528-3

29. Venkata, G., Babu, R., Tolera Masissa, D.: Fixed points in b-metric spaces via simulation function. Novi Sad J. Math. 47(2), 133-147 (2017)

30. Wairojjana, N., Došenović, T., Rakić, D., Gopal, D., Kumam, P.: An altering distance function in fuzzy metric fixed point theorems. Fixed Point Theory Appl. 2015, 69 (2015). https://doi.org/10.1186/s13663-015-0318-1

31. Zadeh, L.A.: Fuzzy sets. Inf. Control 8, 338-353 (1965)

Submit your manuscript to a SpringerOpen ${ }^{\circ}$ journal and benefit from:

- Convenient online submission

- Rigorous peer review

- Open access: articles freely available online

- High visibility within the field

- Retaining the copyright to your article

Submit your next manuscript at $\gg$ springeropen.com 